\title{
LA ESTÉTICA DE LO SUBLIME (LONGINO) EN ADAM ZAGAJEWSKI
}

\author{
Concepción López Rodríguez - Ángel E. Díaz-Pintado Hilario \\ Universidad de Granada \\ clopez@ugr.es - aediazpin@ugr.es
}

\begin{abstract}
RESUMEN
En este trabajo se muestra cómo algunas de las ideas fundamentales formuladas por Longino en su tratado Sobre lo sublime están presentes en la estética de Adam Zagajewski. Se presta especial atención a tres aspectos: a) el concepto de lo sublime y la definición de la poesía, b) la estética de la recepción y c) el papel que la inspiración desempeña en la creatividad.

Palabras ClaVe: Longino, lo sublime, Adam Zagajewski, estética, poesía.
\end{abstract}

\section{ABSTRACT}

"Adam Zagajewski's aesthetics of the sublime (Longinus)». In this paper it is shown how some of the main ideas formulated by Longinus in his treatise On the Sublime are present in the aesthetics of Adam Zagajewski. Special attention is paid to: a) the concept of the sublime and the definition of poetry, b) the aesthetics of reception, and c) the role that inspiration plays in creativity.

KEY WORDS: Longinus, the sublime, Adam Zagajewski, aesthetics, poetry.

Entre las obras de Zagajewski se encuentra En defensa del fervor, publicada en el año 2002, libro compuesto de trece ensayos, distribuidos en cinco secciones. Pues bien, con el segundo ensayo de la sección primera, titulado «Observaciones acerca del estilo sublime», Adam Zagajewski ${ }^{1}$ ha inscrito definitivamente su nombre en la dilatada y brillante historia de la recepción de Longino ${ }^{2}$ en las letras polacas. Y no es este, ni mucho menos, el único texto de su autoría en que Zagajewski se refiere — para reivindicarlo, para rehabilitarlo- a lo sublime. Léase, por poner un solo ejemplo, el siguiente pasaje de En la belleza ajena (2003: 246-247):

La categoría de lo sublime en poesía —imprescindible allí donde se llega al encuentro con el misterio- es un puro fraude para los cínicos o los escépticos; en el mejor de los casos, hipocresía. Usted está fingiendo, eso no existe, usted lo hace por dinero, o tal vez para hacerse famoso... O por esnobismo... Pero, al cabo del tiempo, incluso el poeta mismo empieza a sospechar un fraude, por dos motivos: primero, porque oye esas maledicencias (a veces pronunciadas de un modo balbuciente y, por lo 
menos, divertido); y segundo, porque él mismo se acerca raramente a esa categoría, muy de tarde en tarde. Puede incluso imaginarse a un poeta que experimenta lo sublime y necesita para ello un estilo exaltado, pero precisamente porque se trata aquí de una experiencia de día de fiesta, que se hace esperar mucho, entre semana se convierte en un tanto irónico perseguidor de la poesía. Ocurre así porque, debido a razones desconocidas, todo lo grande sólo consigue crecer en nuestro mundo con dificultad. Lo sublime se convierte en duda fácilmente, con una facilidad extraordinaria. El regreso a la cumbre es ya más difícil. Las leyes de la gravedad actúan incluso aquí... Cuán frágil es la categoría de lo sublime, cuán amenazada está; y, sin embargo, es nuestro último punto de observación, una avanzadilla alejada hacia la cumbre.

Tras admirar las precisas palabras del poeta, y dado que lo sublime presenta un desglose temático amplio, con vistas a establecer una clara diferenciación de matices en los aspectos que aquí se van a contemplar, procederemos estableciendo epígrafes diferenciados.

\section{REIVINDICACIÓN DE LO SUBLIME. «LO SOBRENATURAL»DE LONGINO Y «EL MISTERIO DEL MUNDO»DE ADAM ZAGAJEWSKI}

Al frente de las páginas que integran el ensayo «Observaciones acerca del estilo sublime» figura una cita del poeta suizo, afincado en Francia, Philippe Jaccottet, que anuncia el contenido general y la tesis central de las mismas: Il n'est pas de poésie sans hauteur... Así, pues, de lo que aquí se trata es de la "elevación» en la poesía; propiamente, del estilo elevado; en otras palabras, de lo sublime. Y lo primero que constatamos es que lo sublime, precisamente, es algo que Zagajewski echa de menos en el grueso de la producción cultural de Occidente en nuestros días. El escritor polaco afirma que no le interesa en este ensayo suyo hacer un diagnóstico de la situación, sino presentarla tal como él la ve, anotar un puñado de impresiones y compartirlas con el lector. A nuestro entender, sin embargo, lo que nuestro poeta nos brinda en este ensayo es algo más: nada menos que un profundo y lúcido examen de la cultura actual. En «Observaciones acerca del estilo sublime» (2005: 35-36) leemos, en efecto, lo siguiente:

Tengo la sensación de que en la actualidad nuestra producción espiritual padece de cierta mediocridad, anemia y pequeñez. En nuestra producción actual salta a la vista la desproporción entre las palabras elevadas y las palabras bajas, entre la expresión potente de la espiritualidad y el interminable parloteo de unos menestrales muy

${ }^{1}$ Según nos muestra Jarosław Płuciennik (2000: 259).

${ }^{2}$ Decimos Longino y no Pseudo-Longino (que sería para muchos lo correcto filológicamente hablando) por respetar la opción del poeta polaco y, de este modo, evitar ambigüedades. 
contentos de sí mismos - lo cual se pone especialmente de manifiesto en el caso de la poesía-; me parece que nos encontramos ante una especie de appeasement cobarde con su inevitable política de quiebros y concesiones respecto a la vocación literaria. Y me parece también que uno de los principales síntomas de esta debilidad es la atrofia del estilo elevado y el predominio apabullante del estilo bajo, coloquial, tibio e irónico.

Y, sin embargo, advierte Adam Zagajewski, «mirándolo bien, muy poco nos separa de Longino, que a principios de nuestra era escribió su disertación ya clásica sobre lo sublime» (2005: 41). Longino, precisamente, quien, como afirma David Estrada Herrero (1988: 633), es, junto con Quintiliano, uno de los pocos escritores antiguos que han puesto «entusiasmo, belleza poética e instinto de creación en la crítica literaria $»^{3}$. Consideramos que los tres conceptos antedichos vale la pena subrayarlos, por cuanto constituyen tres conceptos fundamentales también en la estética de Adam Zagajewski. Por su parte, Edgar de Bruyne (1951: 353) considera que en el tratado Sobre lo sublime «la idea central es la de la infinitud del alma espiritual». Pero escuchemos al propio Longino ${ }^{4}$ (35, 2-3):

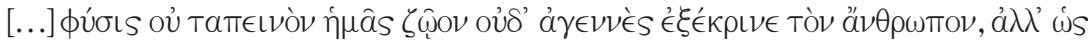

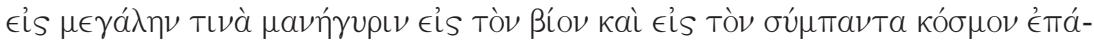

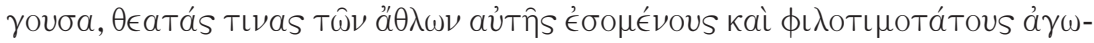

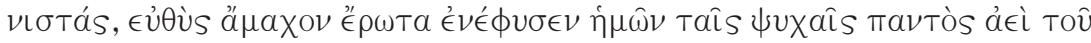

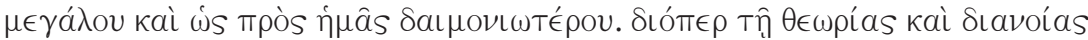

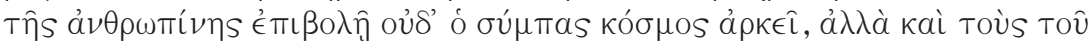

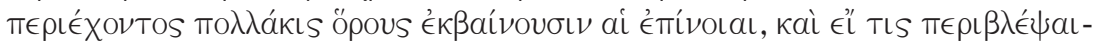

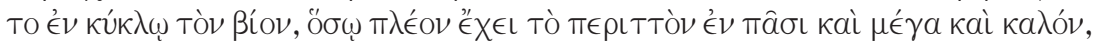

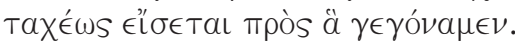

[...] la naturaleza no ha elegido al hombre para un género de vida bajo e innoble, sino que introduciéndonos en la vida y en el universo entero como en un gran festival, para que seamos espectadores de todas sus pruebas y ardientes competidores, hizo nacer en nuestras almas desde un principio un amor invencible por lo que es siempre grande y, en relación con nosotros, sobrenatural. Por esto, para el ímpetu de la contemplación y del pensamiento humano no es suficiente el universo entero, sino que con harta frecuencia nuestros pensamientos abandonan las fronteras del mundo que los rodea y, si uno pudiera mirar en derredor la vida y ver cuán gran participación tiene en todo lo extraordinario, lo grande y lo bello, sabría, en seguida, para qué hemos nacido.

\footnotetext{
${ }^{3}$ Las cursivas son nuestras.

${ }^{4}$ La traducción que se ofrece de los textos citados de Longino es de J. García López (1979).
} 
Según Estrada Herrero (1988: 633), «para Longino lo sublime es lo elevado». También lo es, desde luego, para Zagajewski, como queda de manifiesto en el mismo título de su ensayo: «Observaciones acerca del estilo elevado». Claro que hoy —advierte el poeta polaco (2005: 43) — hemos de concebir lo sublime de un modo distinto de como se ha entendido a veces; hoy, en efecto, es menester purificar lo sublime de toda pomposidad neoclásica, de todo exceso de teatralidad, de todo engolamiento, de toda hinchazón; es más: «un estilo elevado desprovisto de un sentido del humor lleno de indulgencia para con nuestro mundo ridículo, cruel e imperfecto se asemejaría a las canteras de la Carrara toscana, de donde ya se ha extraído todo el mármol y sólo queda la blancura» (2005: 49). Supuesto el estilo elevado, a su juicio irrenunciable, para Adam Zagajewski (2005: 43-44) «[...] hoy, lo sublime es en primer lugar una experiencia del misterio del mundo, un escalofrío metafísico, una gran sorpresa, un deslumbramiento y una sensación de estar cerca de lo inefable (naturalmente, todos estos escalofríos tienen que encontrar una forma artística)». Unas páginas más adelante (2005: 49), lo formulará de esta otra manera, aún más concisamente: «el estilo elevado nace como una respuesta a la trascendencia, una reacción al misterio, a lo supremo».

Llegados a este punto, queda ya, a nuestro entender, muy clara la íntima relación existente entre «lo sublime»y ese «fervor» ( «żarliwos'c) que figura en el mismo título de la colección de ensayos de Adam Zagajewski: los dos responden, en efecto, al unísono ante el misterio del mundo y su belleza, y el asombro que suscita; y conviene recordar aquí las siguientes palabras de Zagajewski sobre el fervor: «El fervor, el ardoroso canto del mundo al que respondemos con nuestro propio canto lleno de imperfecciones» (2005: 26). Podría muy bien decirse, entonces, que «lo sublime» es el lenguaje propio del «fervor», el lenguaje en el que el «fervor» naturalmente se expresa. Ahora bien, como ha observado muy perspicazmente, a nuestro juicio, Anna Czabanowska-Wróbel (2005: 143), el fervor no excluye la distancia, el distanciamiento. Y Adam Zagajewski, como si previera el peligro de que la encendida defensa del fervor que hace en sus ensayos se comprendiese mal o, incluso, pudiera reducirse, por así decirlo, a unas cuantas consignas estéticas, en un poemilla que lleva por título — título un tanto irónico— «En defensa de la poesía, etc.», reivindica un contrapeso para la elevación, reivindica lo cotidiano; lo cotidiano, sí, que — como ha observado asimismo Czabanowska-Wróbel (2005: 46) — puede, empero, elevarse a las alturas de lo místico: «Sí, en defensa de la poesía y del estilo elevado, etc., / pero también una tarde estival en un pueblo, / cuando huelen los jardines y los gatos están quietos / delante de las casas, como filósofos chinos» (Zagajewski, 2007: 46).

Tenemos, pues, que la poesía y el arte en general vienen a responder necesariamente a la llamada de eso que Zagajewski ha denominado el «misterio del mundo», y responden a él plasmándolo en forma, en forma poética y, en general, en forma artística; es decir, dotándolo de voz, literaria, plástica o musical. Resulta, entonces, que, de modo análogo a como el filósofo, espoleado por el asombro, responde a ese misterio cultivando la metafísica, el artista responde escribiendo poemas, pintando cuadros o componiendo sonatas. $\mathrm{Y}$ ¿no está lo que dice Zagajewski en consonancia con lo que nos decía Longino cuando nos hablaba de ese a modo de "gran festival» o fiesta solemnísima de la vida y el universo a que el hombre está convocado? Porque 
— recordemos— «[...] la naturaleza [...] hizo nacer en nuestras almas desde un principio un amor invencible por lo que es siempre grande y, en relación con nosotros, sobrenatural» $(35,2)$.

\section{ESTÉTICA DE LA RECEPCIÓN: LONGINO, HAROLD BLOOM Y ADAM ZAGAJEWSKI}

El modus operandi de lo sublime no consiste en procurar convencer lenta y paulatinamente; es, por el contrario, algo que nos sobreviene y nos sobrecoge, que nos infunde asombro y estupefacción; es un «tirón» hacia lo alto que, con fuerza incontrastable, nos conduce fuera de nosotros mismos, nos arrebata y nos hace gustar los goces supremos, que dejan en la memoria una huella imborrable. Levantada, subida hacia las alturas cimeras, siéntese el alma llena de alegría y aun henchida de orgullo, como si ella misma hubiera producido lo sublime revelado en lo que ve u oye. Y «ino es esto —anota De Bruyne al margen (1951: 356) — porque lo sublime revela al alma su infinitud? ¿No es por este motivo por lo que ella, al darse cuenta de lo sublime, juzga que esto siempre debería deleitar a todos?». Escribe Longino (7, 2-3):

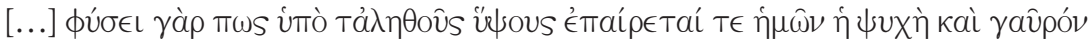

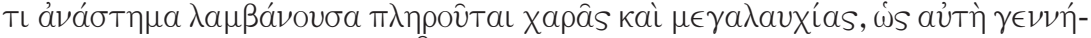

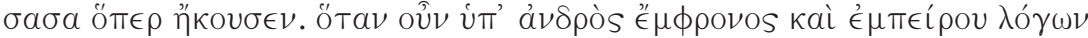

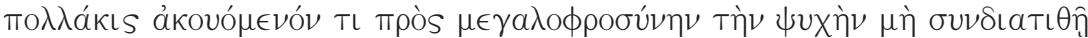

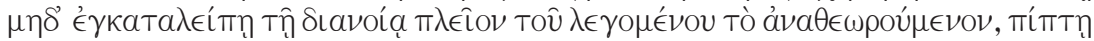

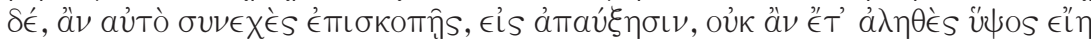

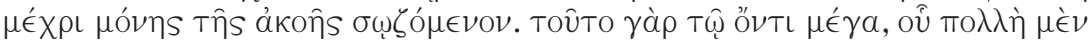

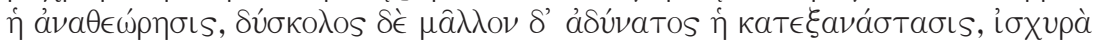

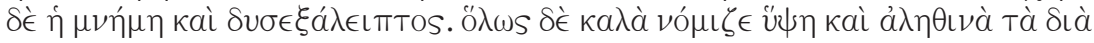

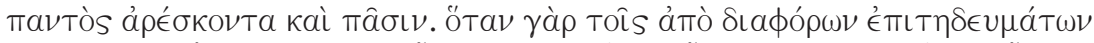

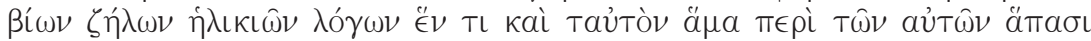

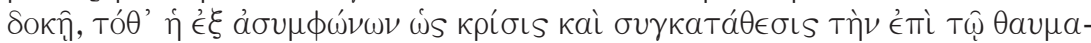

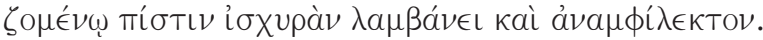

Nuestra alma se ve por naturaleza transportada en cierto modo por la acción de lo verdaderamente sublime, y, adueñándose de ella un cierto orgullo exultante, se llena de alegría y de orgullo, como si fuera ella la autora de lo que ha escuchado. Cuando un hombre sensato y versado en la literatura oye algo repetidamente y su alma no es transportada hacia pensamientos elevados, ni al volver a reflexionar sobre ello tampoco queda en su espíritu más que meras palabras, que, si las examinas cuidadosamente, se convierten en algo insignificante, entonces se puede decir con toda seguridad que no es algo verdaderamente sublime, ya que sólo se conservó mientras era escuchado. Pues, en realidad, es grande sólo aquello que proporciona material para nuevas reflexiones y hace difícil, más aún imposible, toda oposición y su recuerdo es duradero e indeleble. En una palabra, considera hermoso y verdaderamente sublime aquello que agrada siempre y a todos. Pues, cuando personas de diferentes costumbres, vidas, aficiones, edades y formas de pensar tienen una opinión unánime sobre una misma cosa, entonces este juicio y coincidencia de espíritus tan diversos son una garantía segura e indudable en favor de lo que ellos admiran. 
A la vista de este texto de Sobre lo sublime, y puestos a destacar una entre todas las aportaciones de Longino, destacaríamos, con Antonio López Eire, su estética de la recepción. Y, por más que tampoco Adam Zagajewski hable de «estética de la recepción", resulta de todo punto evidente que, siquiera de modo implícito, se ocupa de ella, y también que la estética de la recepción de este poeta polaco contemporáneo viene a coincidir ampliamente con la expuesta por el clásico Longino. Escribe López Eire (2002: 165-166), para quien, por cierto, resulta inequívoca la filiación platónica de la doctrina longiniana:

Una obra literaria no es sino eso, una obra digna de admiración y consideración precisamente porque produce un especial efecto emocional en las almas de sus oyentes o lectores, y punto. Ese efecto emocional es avasallador e irresistible. Ante él hay que rendirse sin condiciones. [...]

El autor transmite al oyente o lector una especie de embriaguez, de éxtasis, de encantamiento, que los une ya uno a otro inseparablemente para siempre. Estamos de nuevo ante la doctrina platónica de la participación del público en la divina manía o locura poética del vate que transmite su éxtasis o desvarío a quienes le escuchan de modo similar a como el imán transmite su magnetismo a toda una cadena de anillos allegados uno al otro (Platón, Ion 533D-E).

En el «Prefacio y preludio» a su ya clásica — y tal vez aún polémica— obra El canon occidental. La escuela y los libros de todas las épocas, Harold Bloom (1994: 12) nos presenta a veintiséis escritores que considera "canónicos», elegidos «tanto por su sublimidad como por su naturaleza representativa»; y en el capítulo I — «Elegía al canon»- aparece el nombre de Longino (1994: 27). Por otra parte, en la introducción — «Qué es el genio?»— a otro libro suyo, el que lleva por título Genios. Un mosaico de cien mentes creativas y ejemplares, y a la hora de caracterizar, precisamente, la genialidad artística, Bloom vuelve a remitirse de buen grado a Longino y lo sublime, y reivindica conceptos tales como los de "grandeza», «lo trascendental» y «lo extraordinario», que quizás — reconoce- no estén de moda, pero que considera de todo punto irrenunciables a la hora de referirse a la experiencia estética (y obsérvese, de paso, cómo en la defensa, más bien a contracorriente, que hace de tales conceptos, a menudo tan maltratados por la crítica literaria actual, Harold Bloom está en sintonía con el pensamiento de Adam Zagajewski). Merece la pena transcribir aquí algunas líneas de Genios (Bloom, 2002: 32):

[...] El antiguo crítico Longino llamó al genio literario lo Sublime, y se dio cuenta de que funcionaba como una transferencia de poder del autor hacia el lector:

Al ser tocada por lo verdaderamente sublime, el alma se exalta naturalmente, se eleva hasta la orgullosa altura, se llena de júbilo y jactancia, como si ella misma hubiese creado esta cosa que ha oido. [(7,2)]

El genio literario es difícil de definir y depende de una lectura profunda para su verificación. El lector aprende a identificar lo que él o ella sienten como una grandeza que se pueda agregar al yo sin violar su integridad. Quizás la "grandeza» no esté de moda, como no está de moda lo trascendental, pero es muy difícil seguir viviendo sin la esperanza de toparse con lo extraordinario. [...] 
En efecto, Adam Zagajewski no solo se resiste a arrumbar el viejo tratado de Longino, sino que también, y en defensa de sus postulados estéticos fundamentales, salta a la arena de la literatura contemporánea como paladín de lo sublime. Y es de resaltar el hecho de que, a la hora de referirse al texto de Longino, y tras subrayar su idea de que lo sublime no puede definirse en términos puramente formales, Zagajewski se quede, reformulada, con la misma cita que Bloom: lo sublime «una chispa que salta del alma del escritor a la del lector» (2005: 41). Si bien no por entero a la letra, Zagajewski permanece del todo fiel al espíritu de Longino, al tiempo que nos ofrece in nuce la clave de su pensamiento estético: la poesía es una "chispa» — «fuego», «luz», «deslumbramiento», "revelación»: términos clave zagajewskianosque salta del alma del poeta a la del lector; en otras palabras, la poesía es un puente tendido entre el poeta y el lector; si se quiere, entre el emisor y el receptor; en definitiva, entre un yo y un tú; la poesía es un mediador; sirviéndonos de un concepto platónico muy querido por Zagajewski, la poesía es, en fin, $\mu \epsilon \tau \alpha \xi \hat{u}^{5}$. Y lo que se dice aquí de la poesía puede, hacerse extensivo al resto de las bellas artes. ¿№ sigue vigente, entonces, la doctrina longiniana? ¿No seguimos esperando — con ilusiónesa «chispa»?, se pregunta Adam Zagajewski (2005: 41):

Porque lo que esperamos de la poesía no es el sarcasmo, la ironía, la distancia crítica, la sabia dialéctica ni el chiste inteligente (aunque todas estas virtudes de la mente cumplen su papel a la perfección siempre que se hallen en su sitio, en un tratado lleno de erudición, un ensayo o un artículo publicado en un periódico de oposición), sino la visión, el fuego y la llama que acompaña los descubrimientos espirituales. En otros términos, lo que esperamos de la poesía es la poesía.

Seguimos estando necesitados, pues, del estilo sublime, en esta época nuestra, «tan poco heroica», en la que somos testigos de la «traición de los intelectuales» (2005: 43). Pero, a juicio de Adam Zagajewski, «un intelectual contemporáneo debería abrirse a lo que está más allá del horizonte de los no-intelectuales; debería pensar y juzgar el mundo sin sucumbir a la presión del espíritu de la época» (2005: 43). Para el poeta y pensador polaco se trata de «un gesto peligroso» (2005: 41), ya que se corre el riesgo de romper, así, en pedazos «el rico tejido de la realidad que hemos recibido en herencia de las generaciones que nos precedieron, y que deberíamos transferir - intacto- a las generaciones que nos seguirán» (2005: 41-42). Surge a este respecto una interrogación inquietante, mas no por ello menos ineludible, para el poeta de estos principios del siglo XXI que es Adam Zagajewski (2005: 48-49):

5En íntima relación con la de «lo sublime» y con la de «inspiración», la idea de $\mu \epsilon \tau \alpha \xi \dot{v}$ (Pl. Smp.) ocupa un lugar central y desempeña un papel de primer orden en la estética de Adam Zagajewski. Léase, al respecto, el primero de los ensayos que integran En defensa del fervor y que da título al libro (páginas 11-34 de la edición citada). 
¿Todavía sabemos escribir como Hölderlin, Norwid, Yeats, Rilke, como Mandelstam y Miłosz, escribir para referirnos a la totalidad del mundo, a un mundo que abarca la divinidad, el dolor, la desesperación y la alegría, y no, a modo del especialista que domina sólo una rama de su oficio, interesarnos sólo por una cosa — da igual: la lengua, la política o las flores de acacia-, convertirnos en un insignificante y astuto artista de un motivo único?

En este texto nos salen al paso ideas de Zagajewski que son recurrentes en su obra: de un lado, la "totalidad» del mundo, una idea capital de algunas de las más profundas y brillantes páginas de sus memorias-diarios En la belleza ajena; de otro, la crítica implacable de la bárbara hiperespecialización a que aparece condenado el hombre - y el artista - de nuestro tiempo, algo que no puede menos de afectar negativamente al estilo sublime. $Y$ es en este contexto de lúcida crítica a nuestra época en el que Zagajewski vuelve de nuevo la vista a sus predecesores, a los grandes poetas del pasado, lejano o reciente, a los poetas ya clásicos o, para el Harold Bloom de El canon occidental, "canónicos». Y es éste el contexto también en el que el poeta polaco nos brinda una nueva caracterización, más matizada y más rica, del estilo elevado, de lo sublime (2005: 49):

El estilo elevado se desprende de una conversación incesante entre dos esferas: la espiritual, cuyos guardianes y creadores son los muertos, como Virgilio en la Divina Comedia, y, por otro lado, la del presens eterno, nuestro camino, nuestro instante único, el cajón del tiempo en que nos ha tocado vivir. El estilo elevado hace de intermediario entre los espíritus del pasado y la provisionalidad del presente, entre Virgilio y los jóvenes que, absortos en el rock, se deslizan sobre monopatines por las tersas aceras de las ciudades occidentales, entre el pobre y solitario Hölderlin y los turistas alemanes achispados que por la noche vocean por los callejones estrechos de Lucca, entre lo vertical y lo horizontal.

«Una conversación incesante entre dos esferas»... Es decir, el estilo sublime vuelve a caracterizarse en términos dialógicos, de comunicación entre escritor y lector, quienes, a despecho del abismo espacio-temporal que pueda separarlos - y que, de hecho, de sólito los separa—, se encuentran en el libro, en el acto — en el «diálogo»— de la lectura, precisamente. En este sentido, el estilo elevado desempeña el papel de mediador entre la tradición y el presente. Cierto es que ya Harold Bloom (1994: 27), puesto a definir el canon, había apuntado en esa dirección: «El canon, una vez lo consideremos como la relación de un lector y un escritor individual con lo que se ha conservado entre todo lo que se ha escrito, y nos olvidemos de él como lista de libros exigidos para un estudio determinado, será idéntico a un Arte de la Memoria literario [...].» Pero es claro que para fijar el origen de esta concepción es menester remontarse a Longino, tal vez el primer teórico que haya definido lo sublime $-\mathrm{y}$ lo canónico literario- precisamente en categorías dialógicas. Recordemos lo que

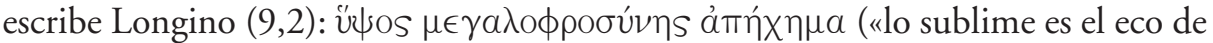
un espíritu noble»). O, como escribe Adam Zagajewski, "una chispa que salta del alma del escritor a la del lector» (2005: 41). 


\section{LA INSPIRACIÓN: LONGINO Y ADAM ZAGAJEWSKI}

Una faceta importante de la estética de Adam Zagajewski, que lo es asimismo de la de Longino, la constituye la idea de la inspiración. Cierto que Longino no le dedica explícitamente ni una línea, mas no lo es menos que, como observa Francisco de P. Samaranch (1972: 29), la idea de la inspiración está «entretejida en todo el tratado como un presupuesto indiscutible y unánimemente admitido». A ella apuntan, en efecto, de modo inequívoco, términos tan frecuentes en la obra longiniana como «posesión», «entusiasmo», «coribante o «bacante». Viene a ser un estado imprescindible en el proceso de la creación artística, estado «que llevará a la producción genial si corresponde a un motivo suficiente y es servido por una "técnica" depurada de la expresión, o a lo contrario si es una actitud superficial y ficticia” (Samaranch, 1972: 30). La inspiración nos remite a una «voz» que el artista oye, que lo atrae con fuerza incontrastable y aun lo arrebata, sin quitarle, por ello, su libertad. Adam Zagajewski, que confiesa haber oído - y, desde luego, escuchado atentamente- esa voz, ha podido escribir de ella (2005: 55):

Una voz que oímos en los momentos de máxima concentración. Aunque esta voz suene una sola vez para no volver a sonar hasta al cabo de muchos años, a partir de entonces todo cambia radicalmente, porque este hecho significa que la libertad que tanto amamos y perseguimos no es nuestro único tesoro; además, aquella voz que a veces oímos no nos la arrebata, sino que nos revela sus límites y nos demuestra que es imposible alcanzar una emancipación absoluta.

Por eso estoy dispuesto a defender el concepto de inspiración [...].

Lo que, desde nuestro punto de vista, particularmente merece subrayarse aquí es el hecho de que Adam Zagajewski, poeta polaco de la segunda mitad del siglo XX y primera del XXI, sigue creyendo en la inspiración, como creía Antonio Machado. Acto seguido, empero, tiene buen cuidado de advertirnos nuestro poeta que la inspiración no exime a nadie de la disciplina y del rigor, pero es ella siempre, bajo la bien conocida figura de la Musa, la que nos conduce a aquella «voz». Un punto más de contacto, pues, de Zagajewski con Longino y su clásica disertación acerca de lo sublime; y una prueba más de la plena inserción —inserción consciente y, diríase,

${ }^{6}$ Esa inspiración Adam Zagajewski la defiende, como no podía ser menos, también durante las entrevistas, cada vez más frecuentes, que le solicitan y concede para revistas literarias y periódicos. Así, en el transcurso de la que en enero de 2006 le hace Jolanta W. Best, Zagajewski expone su personal concepto de "poesía pura» —o, quizá mejor, de "pura poesía» ("pure poetry»)—, que no constituye ningún tipo determinado de poesía, tal y como podría postularse en algún manifiesto, sino que es la poesía misma, la poesía, sin más; la poesía de esos pocos versos — «de dos a cinco»— que le son regalados — «donados»— al poeta en los momentos de inspiración, precisamente. Y resulta que ello proporciona un momento de 
gozosa - de este gran escritor polaco contemporáneo en la entera tradición de la cultura occidental, que se remonta a los griegos.

\section{UN POEMA ZAGAJEWSKIANO}

Nos parece que nada mejor, para concluir este trabajo, que reproducir aquí otro poema ${ }^{7}$ de Zagajewski (2005: 24-25): el que lleva por título —así, en italiano«Senza flash» («Senza flash»). No es, desde luego, el único, pero sí uno de los que, entre todo los suyos, más expresivamente pueden servir, por así decirlo, de ilustración a la estética de lo sublime - de confesa filiación longiniana - de este gran poeta polaco que es Adam Zagajewski:

$$
\begin{array}{r}
\text { "Senza flash!» (Sin flash) } \\
\text { (prohibición que se oye con frecuencia } \\
\text { en las galerías de Italia) }
\end{array}
$$

Sin llamas, sin noches de insomnio, sin brasas, sin lágrimas, sin una gran pasión, sin convicción, así viviremos; senza flash.

Tranquila y regularmente, soñolientos y obedientes, manchadas las manos con la tinta negra de los periódicos, caras grasientas de crema; senza flash.

Turistas sonrientes con sus impecables camisas, Herr Lange y Miss Fee; y Monsieur et Madame Rien entrarán en el museo; senza flash.

felicidad, felicidad de la que — nótese bien — tanto el poeta como el lector pueden participar (recuérdese: «una chispa que salta del alma del escritor a la del lector» (Zagajewski, 2005: 41).

JWB: What is pure poetry?

AZ: It is two to five of the most successful lines in a poem. These lines create the poem, or the soul of the poem. Most of the time I never know myself which lines are purely poetic lines.

JWB: Thus pure poetry is like epiphany. It happens suddenly, almost like bliss.

AZ: This is something that the poet receives. It is a gift of a few successful lines in a poem, but it is never the entire poem. I think it is almost impossible to write a whole poem which consists only of this gift. A poet works with the environment. Roads leading to purely poetic lines are "ascending" or "descending". I try to find a few lines of pure poetry, but I do not mean "pure poetry" in the sense of a poetic manifesto. Sometimes pure poetry is perceived as hermetic poetry. That is not what I mean. "Pure poetry" indicates a few utterly successful lines in a poem. It provides a moment of happiness. The reader and poet can equally embrace this happiness through pure poetic lines.

${ }^{7}$ Nos parece este poema digno Homenaje a Isabel García Gálvez que sin duda sintió y vivió la llamada de lo Sublime. 
Se situarán ante el cuadro de Piero della Francesca

en el que Cristo, casi enajenado, emerge de la tumba, resucitado, libre; senza flash.

Y quizá entonces ocurra algo imprevisible, oculto en suave algodón, el corazón se conmueva, se haga el silencio, brille un flash.

\section{REFERENCIAS BIBLIOGRÁFICAS}

\section{LONGINO}

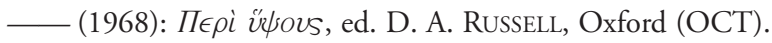

- (1979): LONGINO. Sobre lo sublime, introducción, traducción y notas de José GARCía LóPEZ, Biblioteca Clásica Gredos, no 15, Gredos, Madrid.

\section{OBRAS DE ADAM ZAGAJEWSKI}

— (2003): En la belleza ajena, trad. (<pol. W cudzym pięknie, 1998) de Ángel Enrique Díaz-PINTADO Hilario, Pre-Textos, Valencia.

- (2005): Deseo, trad. (<pol. Pragnienie, 1999) de Xavier Farré Vidal, Acantilado, Barcelona.

— (2005): En defensa del fervor, trad. (<pol. Obrona żarliwości), 2002) de Jerzy SŁAWOMIRSKI y Anna Rubió, Acantilado, Barcelona.

(2007): Antenas, trad. (<pol. Anteny, 2005) de Xavier Farré Vidal, Acantilado, Barcelona.

\section{ENTREVISTA CON ADAM ZAGAJEWSKI}

BEST, J. W. (2006): "Poetry Summons Us to Life". A Conversation with Adam Zagajewski», The Sarmatian Review XXVI (1) [http://www.ruf.rice.edu/-sarmatia/106/261best.html].

\section{BIBLIOGRAFÍA SECUNDARIA}

Bloom, H. (2004 [1994]): El canon occidental. La escuela y los libros de todas las épocas, trad. (<ingl. The Western Canon. The Books and School of the Ages) de Damián Alou, Anagrama, Barcelona.

- (2005 [2002]): Genios. Un mosaico de cien mentes creativas y ejemplares, trad. (<ing. Genius: A Mosaic of One Hundred Exemplary Creative Minds) de Margarita VALENCIA VARGAS, Anagrama, Barcelona.

BRUYNE, E. DE (1963 [1951]): Historia de la estética, t. I: La antigüedad griega y romana, trad. de Armando SuÁrez, O. P., B.A.C., Madrid.

CZabanowska-Wróbel, A. (2005): Poszukiwanie blasku. O poezji Adama Zagajewskiego, Universitas, Kraków.

Estrada Herrero, D. (1988): Estética, Herder, Barcelona.

López EIre, A. (2002): Poéticas y retóricas griegas, Editorial Síntesis, Madrid.

PŁUCIENNIK, J. (2000): Retoryka wzniostości w dziele literackim, Universitas, Kraków.

SAMARANCH, F. DE P. (1972): «Nota preliminar» a LONGINO(?), De lo sublime, traducción del griego, prólogo y notas de Francisco DE P. SAMARANCH. Aguilar, Buenos Aires. 
